\title{
$\therefore$ IJCRR \\ Section: Healthcare \\ Determinants of Sex of Rearing in Late Presenters of 5 Alpha-reductase Deficiency in Developing Society
} ISI Impact Factor (2019-20): 1.628 IC Value (2019): 90.81 $\operatorname{SJIF}(2020)=7.893$

(c) (i) (8)

Copyright@IJCRR

\section{Jain Manish', Jain Alpana ${ }^{2}$}

'Consultant Pediatric Surgeon, SAACHI Children Hospital, Surat, India; ${ }^{2}$ Consultant pathologist, TOUCHLABS, Surat, India.

\section{ABSTRACT}

Introduction: 5 alpha-reductase deficiency is a condition that affects male sexual development before birth and during puberty. Although testosterone is considered a predominant male sex hormone, not all tissues are responsive to testosterone. The 5 alpha-RD2 enzyme converts testosterone into a more potent form of the male sex hormone called dihydrotestosterone (DHT).

Aims and Objective: To propound various factors and their relative importance in guiding the determination of sex of rearing in late presenters of 5 alpha-reductase deficiency in developing society.

Methods: Seven patients of proven 5 alpha-reductase deficiency were prospectively involved in this study between 2011 and 2020. All patients had been raised as females and presented with the ambiguity of genitalia at a later age which is not so uncommon in a developing society due to various factors. Diagnosis of 5 alpha-reductase deficiency was confirmed after various standard tests. Based on male genotype, size of the phallus, response to dihydrotestosterone cream application, socioeconomic factors and wishes of parents and children, sex of further rearing was advised. Repeated elaborate sessions of counselling were an integral and vital part of these decisions.

Results: In view of clinical and laboratory facts, results of medical and surgical interventions, social milieu of the society and personal choice of patients and their family, comprehensive counselling was done and six out of seven patients were advised, and accepted, change of sex of rearing to male and accordingly necessary interventions were done. One patient opted and continued to be reared as female. Quality of life, acceptability in society and most importantly, ability to make a living on its own, were followed, studied and analysed.

Conclusion: Clinical facts, social realities, employment avenues, social stigma, infertility and many other factors suggest that, in a developing society, it is strongly advisable to consider the change of sex of rearing to male in all late presenters of 5 alphareductase deficiency.

Key Words: 5 alpha-reductase deficiency, late presenters, sex of rearing, developing society, Surgical interventions, Quality of life

\section{INTRODUCTION}

Deficiency of enzyme, 5-alpha-reductase type 2 (ARD) gene leads to an uncommon autosomal recessive sex-limited condition resulting in the impaired conversion of testosterone to the more physiologically active dihydrotestosterone (DHT). Because decreased production of DHT has led to defective external genitalia in utero, genetic males with 5 -alpha-reductase type 2 deficiency are born with ambiguous genitalia. ${ }^{1}$ These patients with 5 -ARD usually present with variable ambiguity of the genitalia due to varying degree of under androgenization with a clitoral-like phallus, severely bifid scrotum, pseudovaginal perineoscrotal hypospadias and a rudimentary prostate. Occasionally, patients can appear more masculinized, can also lack a separate vaginal opening, have a blind vaginal pouch that opens into the urethra, and have removed penile hypospadias or maybe a penile urethra. ${ }^{2}$ Mullerian structures like the uterus and fallopian tubes are absent because of the normal secretion of the müllerian-inhibiting factor. Testes are intact and are usually found in the inguinal canal or scrotum; however, cryptorchidism is frequently described with testes occasionally located in the abdomen. Because the Wolffian duct develops normally owing to normal fetal testosterone levels, the ejaculatory ducts, epididymides, vasa deferentia, and seminal vesicles are formed. The prostate is small, nonpalpable

\section{Corresponding Author:}

Dr. Jain Manish, A-901, Sangini Residency, near Panas Gam, Canal Road, Surat-395017, India.

ISSN: 2231-2196 (Print)

Received: 24.08 .2021
ISSN: 0975-5241 (Online)

Revised: 12.09 .2021
Accepted: 09.10.2021
Published: 13.12 .2021 
and rudimentary but few may grow under the influence of pubertal surge. ${ }^{3}$ The Partial virilization of males with 5-ARD occurs at puberty and may be attributable to the rise in type 1 enzyme activity at that time. ${ }^{4}$

Many individuals with 5-alpha-reductase type 2 deficiency are identified in the neonatal period because of ambiguous genitalia. ${ }^{5}$ However, some of these children are not diagnosed in the neonatal period due to a variety of reasons and continue to be raised as females but, by puberty, most of them present with striking ambiguity of genitalia. Clear signs of virilization predominate at this age. The phallus or hypertrophied clitoris exhibit definite enlargement. The shoulders are relatively broad and the hips are narrow. Muscularity and body hair may increase. No breast development is generally present. A prominent Adam's apple may start to develop. Facial hair develops. The child's voice may begin to deepen. The mucosa of the vaginal introitus remains atrophic in appearance (remaining red) rather than the thickened pink colour of estrogen-stimulated mucosa. Elevated serum testosterone-to-DHT ratio (T/DHT) is the hallmark of 5-alpha-reductase type 2 deficiency. Typically, testosterone levels are normal to modestly elevated and DHT levels are low to undetectable.

Variable age of presentation, disparate clinical picture and unpredictable and varying outcomes of patients with disorders of abnormalities in androgen response or synthesis place an ethical and potentially legal burden on the treatment team to ensure that every patient is treated following broad principles of treatment of disorders of sexual differentiation (DSD). This is especially true for gonadectomy and/or genioplasty, irreversible procedures that result in loss of potential fertility, and have a life-long impact on gender satisfaction. The more practical approach, to delay definitive therapy, has developed over the last 2 decades as adult intersex patients and advocates have voiced their dissatisfaction with lifechanging procedures performed prematurely to their ability to consent. Further compounding the issue are the typical socioeconomic and cultural factors which create a complex interplay of issues affecting the decision of sex of rearing including reassignment of sex.

Full disclosure of the diagnosis, prognosis (gender identity outcome as well as the potential for fertility and sexual function), rationale with risks and benefits for proposed procedures, alternative treatments, and local clinical experience must be shared under the standard of informed consent. ${ }^{6} \mathrm{Mul}-$ tiple factors must be considered in recommending gender reassignment for children born with ambiguous genitalia but present late in life. These include diagnosis, genotype, genital appearance, response to medication, surgical options, the potential for fertility, the potential need for lifelong hormone replacement therapy, and the particular social, religious, and cultural context of the family. Other factors include expected quality of life, wishes of parents and patients, acceptability in society and ability to make living on its own. The ultimate medical goal of treatment is to repair external genitalia as near a nonambiguous look as feasible at the same time as preserving full sensation, the capacity for sexual satisfaction (to consist of penetrative intercourse), and ideally, fertility.

In patients with $5-\mathrm{ARD}$, endorse that testosterone remedy may additionally increase penile shaft length and circumference, increase erectile efficiency and ejaculatory quantity, boom facial hair and muscularity, and improve a sense of well being. ${ }^{7,8}$ Various penile enhancement techniques are available and are directed at increasing penile dimensions but lack of standardization of procedures and disappointing short-term and long-term patient satisfaction rates are reported. ${ }^{9}$ Patients with 5-alpha-reductase deficiency who have not undergone feminizing procedures may be fertile; however, most of this subpopulation requires in vitro fertilization or other assisted-fertilization techniques. ${ }^{10}$ Recent data suggest that reconsidering the past policies of raising children with $46 \mathrm{XY}$, such as those with 5-ARD, with ambiguous genitalia and small phalli, as females may be appropriate.

\section{MATERIAL AND METHODS}

Seven patients of proven5-ARD were prospectively studied between March 2011 and October 2020. All persons and their parents gave their informed consent before their inclusion in the study. The deficiency of this enzyme was confirmed by elevated testosterone to DHT ratio after stimulation with Human Chorionic Gonadotrophin (HCG). Karyotyping was done in all patients which were $46 \mathrm{XY}$ in all. Only those patients were included in the study who had presented after 10 yrs of age and till that time they were raised as normal females because either the ambiguity of genitalia was not there or parents didn't pay attention or ambiguity was minimal or they were not having access to the appropriate healthcare system. After a full workup of patients to confirm the exact clinical condition of $5 \mathrm{ARD}$, sex confirmation or reassignment issue was discussed with parents and relatives in detail. All patients, except one, were reassigned sex as male and raised accordingly. These patients were prospectively followed, from zero to 11 years, on basic parameters of quality of life (QOL) which included adaptation, fulfilment, happiness, inclusivity, employment opportunities, sexual pleasure, social security, self-esteem and societal acceptance. A questionnaire was prepared, in consultation with the clinical psychologist, related to each parameter and on that basis analysis of various responses was done. Patients were called periodically and in the entire series, home visits were undertaken to know more from family members, relatives and neighbours. This also helped in understanding more about social factors. Out of seven, three patients were from a single extended family with a strong history of consanguinity. They 
were approached and diagnosed after the first case was seen and the diagnosis confirmed.

\section{RESULTS}

Out of the seven patients who were included in the study, six were reassigned the sex and further raised as males. One patient continued to be raised as a female. All reassigned male patients were happily adopted in the family, school and society after elaborate counselling sessions were done at various levels. The level of adaption and societal acceptance was far less than optimal for the sole female patient after the primary disease was known to people. Due to various factors, this patient scored poor on the points of self-esteem, inclusivity and happiness also. Her scholastic performance suffered badly and finally, she left the school and was relocated. At the same time reassigned male patients were seemingly happy with their new role in life and coped well with initial adaptation problems. All these patients had a satisfactory erection, ejaculation and three of them were doing occasional masturbation. Two of them got married and were able to have sexual intercourse with penetration. Both fathered children, one by in vitro fertilisation and one with regular use of DHT after marriage. All of them were employed with meaningful jobs or professions of various levels. A sole female patient was not employed, dependent on her parents and the family suffered from major social stigma and rejection.

\section{DISCUSSION}

Some peculiar socioeconomic factors play an important role in the social dynamics of a developing country or developing society like India. The healthcare scenario in general and specialist care in particular, in major parts of India, is not very promising. Specialists and super-specialist care about not so common clinical conditions that are either not available or not accessible in remote and even not so remote areas of our country. Poverty, ignorance, lack of health awareness and apathy of the state also play a very important role in complicating the situation. All these cases were from rural areas and because of the above reasons, in all patients, parents were completely unaware of ambiguity of genitalia till puberty when, gradually, they noticed striking ambiguity in genitalia.

Based on male genotype, size of the phallus, response to dihydrotestosterone cream application, socioeconomic status and wishes of parents and children, sex of further rearing i.e. sex reassignment was advised. While confirmation of male genotype by karyotyping forms the main basis of gender decision, the size of the phallus and its response to DHT cream corroborates the decision. However, during and after counselling of patient and parents, socioeconomic conditions should be given utmost importance while discussing and deciding the future sex of rearing.

India has traditionally been a male-dominated society and despite many social advancements and educational progress few social taboos are still prevalent and this is reflected in society's attitudes and practices towards the female sex. It starts from antenatal periods where female feticide ${ }^{11}$ is rampant in many communities and this discrepancy may continue before and even after marriage. What complicates the matter here is the fact that patients having 5- ARD are neither genetically female nor may continue their life as completely normal females because they can never bear any children. Social acceptance and attitude towards indeterminate sex is also very unpredictable and sometimes dangerous. At the same time, being a male-dominated society, life as an independent male, which even genetically he is, is far more smooth and easy especially in lower socioeconomic strata of society and from earning potential point of view. Another very important aspect is that since they are genetically male and medical and surgical management has repaired and overcome phenotypic and morphological deficiencies they may have a completely normal sexual life. Fertility by both in vivo [Personal communication] and in vitro ${ }^{12}$ methods has also been proven by various studies. All these factors give them maximum opportunities and chances to lead a normal social and personal life by helping patients in transition from female rearing to male rearing. This study also emphasizes the fact that the role of treating pediatric surgeon and his team goes much beyond the clinical corrections and it is the primary responsibility of treating team members to bring this unusual circumstance of change of sex of rearing to a logical conclusion based on scientific evidence and in sync with social and cultural realities and ensure that transition and establishment into new identity are smooth.

While counselling the parents, all except one, opted for interventions for male reassignment which included Dihydrotestosterone cream (DHT), bilateral orchiopexy with testicular biopsy, hypospadias repair and they were ready and eager to convert the sex of rearing from female to male. These medical and surgical interventions can give a ray of hope to these patients and promise them a respectful life in society. Parents of one patient requested and insisted on continuing with the female sex of their child and this decision was probably out of fear of coping with social challenges. The inherent predilection for male sex in developing society in general and in the Indian subcontinent, in particular, is the basis of this decision by the majority of parents.

On following the social and family life of these adolescents after sex reassignment and reconstructive interventions we found that all these reassigned male children were accepted in society very easily at various stages of their life. The eldest of them is now $22 \mathrm{yr}$ old, working in a bank, married and 
has also fathered a child. Four out of seven fathered children by in vivo or in vitro methods and that was possible only because they were genetic males and raised also as males. This was the main premise of counselling while discussing and deciding about the sex of rearing after diagnosis of 5-AHD deficiency. Four of them were employed meaningfully in reasonably paid jobs, commensurate with their qualifications and experience. Two continued with the parental profession of farming while the child who was raised as the girl didn't marry, could not complete her college education, could not take any profession or job and remained dependent on her parents. She also faced major social stigma and almost ostracisation from society once people came to know about the sexual ambiguity of children. She was never married and her family had to relocate themselves to avoid social stigma.

All these observations and findings make a strong case for male sex reassignment in late presenters of 5 alpha-reductase deficiency, especially in a developing society.

\section{CONCLUSION}

Clinical facts, social realities, employment avenues, social stigma, infertility and many other factors suggest that, in a developing society, it is strongly advisable to consider the change of sex of rearing to male in all late presenters of 5 alpha-reductase deficiency.

Acknowledgement: None do declare

Conflicts of interest: The author declare that there is no conflict of interest.

\section{Funding: Nil}

All human studies have been approved by the appropriate ethics committee and have therefore been performed following the ethical standards laid down in the 1964 Declaration of Helsinki.

\section{REFERENCES}

1. Houk CP, Lee PA. Consensus statement on terminology and management: disorders of sex development. Sex Dev. 2008; 2 (4-5):172-80.

2. Silver RI, Russell DW. 5alpha-reductase type 2 mutations are present in some boys with isolated hypospadias. J Urol. Sep 1999; 162 (3 Pt 2):1142-5.

3. Imperato-McGinley J, Zhu YS. Androgens and male physiology the syndrome of 5alpha-reductase-2 deficiency. Mol Cell Endocrinol. Dec 30 2002; 198 (1-2):51-9.

4. Zhu YS, Imperato-McGinley JL. 5alpha-reductase isozymes and androgen actions in the prostate. Ann N Y Acad Sci. Feb 2009; 1155: 43-56.

5. 5. Bertelloni S, Scaramuzzo RT, Parrini D, Baldinotti F, Tumini S, Ghirri P. Early diagnosis of 5 alpha-reductase deficiency in newborns. Sex Dev. 2007;1(3):147-51.

6. 6. Informed Consent for Pediatric Genitoplasty or Gonadectomy in Patients with DSDs. AIC Legal. Available at http://www. lgbtbar.org/annual/CLE_materials/3B/GuidelinesforInformedConsent.pdf. Accessed 11/ $103 / 2012$.

7. 7. Mendonca BB, Inacio M, Costa EM,. Male pseudohermaphroditism due to steroid 5alpha-reductase 2 deficiency. Diagnosis, psychological evaluation, and management. Medicine (Baltimore). Mar 1996; 75(2):64-76.

8. 8. Price P, Wass JA, Griffin JE,. High dose androgen therapy in male pseudohermaphroditism due to 5 alpha-reductase deficiency and disorders of the androgen receptor. J Clin Invest. Oct 1984; 74(4):1496-508.

9. 9. Vardi Y, Har-Shai Y, Gil T, Gruenwald I. A critical analysis of penile enhancement procedures for patients with normal penile size: surgical techniques, success, and complications. Eur Urol. Nov 2008; 54(5):1042-50.

10. 10. Wilson BE, Reiner WG. Management of intersex: a shifting paradigm. J Clin Ethics. Winter 1998; 9 (4):360-9.

11. 11. Jha P, Kumar R, Vasa P, Dhingra N, Thiruchelvam D, Moineddin R. Low female[corrected]-to-male [corrected] sex ratio of children born in India: a national survey of 1.1 million households. Lancet 2006; 367:211-8.

12. 12. Matsubara K, Iwamoto H, Yoshida A, Ogata T Semen analysis and successful paternity by intracytoplasmic sperm injection in a man with steroid $5 \alpha$-reductase- 2 deficiency. Fertility and Sterility, 94(7), 2770.e7-2770.e10. 